\title{
Research on the Ultraviolet Aging Performance of RPRS Modified Asphalt
}

\author{
Ning $\mathrm{Li}^{1}$, Wei Huang ${ }^{2}$ \\ ${ }^{1}$ Highway College of Chang'an University, Xi'an, Shaanxi Province, China \\ ${ }^{2}$ The Center of Highway Test and Experiment of Yunnan Province, Kunming, Yunnan Province, China
}

Keywords: RPRS modified asphalt; ultraviolet aging; performance research.

\begin{abstract}
In the experiment, a certain proportion of recycled polyethylene wax (RPEW), crumb rubber modifier (CRM) and styrene butadiene rubber (SBR) are used to produce RPRS asphalt modifier through high temperature pyrolysis and physical mixing process. The modifier is then used to modify the matrix asphalt. Compared with the matrix asphalt, RPRS modified asphalt has better performance at high temperature. In order to verify the ultraviolet aging properties of RPRS modified asphalt, 10 kinds of asphalts (DH, IS, MM, DH3283, DH4283, IS3283, IS4283, MM3283, MM4283, SBS) are chosen and tested from the perspectives of original asphalt, ultraviolet radiation aging (UV) and rolling thin film oven test (RTFOT). Three indicators, namely Penetration, Softening Point and Ductility are adopted. The test results show that, the Penetration of RPRS modified asphalt is attenuated; the Softening Point of RPRS modified asphalt changes little; the Ductility of RPRS modified asphalt decreases limitedly.
\end{abstract}

\section{Introduction}

In China, polyethylene wax has been used for modifying asphalt for a long time. From PE raw materials [1] to recycled agricultural film [2], PE cannot be popularized in large area in China for following reasons. (1) PE needs specialized modification equipments such as high-speed shearing machine. [3] (2) Segregation phenomena are commonly seen. [4] (3) Its performance at low temperature is no better than SBS modified asphalt. [5] (4) Its price is equal to SBS modified asphalt.

At present, there is a new manufacturing technique which employs recycled rubber resin composite to modify asphalt (hereinafter referred to as "PR"). The production process goes as following. (1) The purchased waste plastic material is washed and crushed to get recycled plastics. (2) The recycled plastic is heated up to $470^{\circ} \mathrm{C}$, then keeping at this temperature for 20 minutes without air. The recycling PEW is obtained after the material is cooled. (3) The recycling PEW is heated up to $260^{\circ} \mathrm{C}$ and added with CRM. After stirring for 1 hour, the material is cooled and ultimately gets PR. [6-7]

The test results show that, the density of PR is similar with asphalt. Its melting point is about $120^{\circ} \mathrm{C}$, and it can be completely dissolved in the asphalt at $150^{\circ} \mathrm{C}$ after stirring for 1 hours. In order to solve the problem of PR modified asphalt's performance at low temperature, SBR is also prepared to produce RPRS asphalt modifier. In the research process, the group gradually solved the problem of segregation of modified asphalt at high and low temperature.

Ten types of asphalts (DH, IS, MM, DH3283, DH4283, IS3283, IS428, MM3283, MM4283 and SBS) are tested according to 3 major indicators: Penetration, Softing Point and Ductility.

In order to better distinguish all kinds of modified asphalts, the following naming rules are adopted: abbreviation of asphalt + type of PR + type of SBR + PR mixing amount + SBR mixing amount. For instance, MM3283 means that $8 \%$ of 3\#PR and 3\% of 2\#SBR are used to modify MM asphalt.

The comparison of Penetration, Softing Point and Ductility of asphalt is carried out after adding different amount of rubber resin into the original asphalt, and then mixing and molding the material at a certain temperature. The performances of the Penetration, Softing Point and Ductility of various asphalts needles are compared and analyzed as following. 
Table 1. Performances of Matrix Asphalt and RPRS Modified Asphalt

\begin{tabular}{|c|c|c|c|c|c|c|c|}
\hline Type & $\begin{array}{c}\text { Penetration at } \\
25^{\circ} \mathrm{C}(0.1 \mathrm{~mm})\end{array}$ & $\begin{array}{c}\text { Ductility } \\
\text { at } \\
10^{\circ} \mathrm{C}(\mathrm{cm})\end{array}$ & $\begin{array}{c}\text { Softing } \\
\text { Point }\left({ }^{\circ} \mathrm{C}\right)\end{array}$ & $\begin{array}{c}\text { penetration } \\
\text { index }\end{array}$ & $\begin{array}{c}\text { equivalent } \\
\text { softening } \\
\text { point T800 }\end{array}$ & $\begin{array}{c}\text { equivalent } \\
\text { brittle } \\
\text { point T1.2 }\end{array}$ & $\begin{array}{c}\text { plasticity } \\
\text { range } \Delta \mathrm{T}\end{array}$ \\
\hline MM & 75.0 & 16 & 56.0 & -0.596 & 50 & -15 & 65 \\
\hline DH & 68.0 & 17 & 54.0 & -0.923 & 49 & -12 & 61 \\
\hline IS & 70.0 & 18 & 56.0 & -0.551 & 50 & -14 & 64 \\
\hline SBS & 71.0 & $31\left(5^{\circ} \mathrm{C}\right)$ & 71.0 & -0.066 & 52 & -18 & 70 \\
\hline MM3283 & 38.7 & $>150$ & 71.5 & -0.551 & 56 & -9 & 65 \\
\hline MM4283 & 40.2 & $>150$ & 71.5 & -0.323 & 56 & -11 & 67 \\
\hline DH3283 & 41.1 & $>150$ & 66.5 & -0.506 & 55 & -10 & 65 \\
\hline DH4283 & 39.7 & $>150$ & 69.5 & -0.291 & 57 & -11 & 68 \\
\hline IS3283 & 42.3 & $>150$ & 70.5 & -0.017 & 57 & -13 & 70 \\
\hline IS4283 & 38.7 & $>150$ & 68.5 & 0.067 & 58 & -13 & 71 \\
\hline
\end{tabular}

According to the penetration classification system of China, the Penetration of RPRS modified asphalt is lower than that of the matrix asphalt and SBS modified asphalt; its Softening point is higher than that of the matrix asphalt, and varies little from SBS modified asphalt; its Ductility at $10^{\circ} \mathrm{C}$ shows obvious advantages compared with the matrix asphalt, and shows little difference from SBS modified asphalt. The needle penetration index of RPRS modified asphalt is much lower than that of matrix bitumen, indicating that the temperature sensitivity is reduced.

\section{Research on the Ultraviolet Aging Performance of RPRS Modified Asphalt}

Table 2 Performance of Two Kinds of Asphalt After Aging

\begin{tabular}{|c|c|c|c|c|c|c|c|c|c|}
\hline \multirow[b]{2}{*}{ No. } & \multicolumn{3}{|c|}{ original asphalt } & \multicolumn{3}{|c|}{ RTFOT } & \multicolumn{3}{|c|}{ UV } \\
\hline & $\begin{array}{l}\text { Penetration at } \\
25^{\circ} \mathrm{C}(0.1 \mathrm{~mm})\end{array}$ & $\begin{array}{c}\text { Ductility at } \\
10^{\circ} \mathrm{C}(\mathrm{cm})\end{array}$ & $\begin{array}{c}\text { Softing } \\
\text { Point }\left({ }^{\circ} \mathrm{C}\right)\end{array}$ & $\begin{array}{l}\text { Penetration at } \\
25^{\circ} \mathrm{C}(0.1 \mathrm{~mm})\end{array}$ & $\begin{array}{c}\text { Ductility at } \\
10^{\circ} \mathrm{C}(\mathrm{cm})\end{array}$ & $\begin{array}{c}\text { Softing } \\
\text { Point }\left({ }^{\circ} \mathrm{C}\right)\end{array}$ & $\begin{array}{c}\text { Penetra } \\
\text { tion at } \\
25^{\circ} \mathrm{C} \\
(0.1 \mathrm{~m} \\
\mathrm{m}) \\
\end{array}$ & $\begin{array}{c}\text { Ductility at } \\
10^{\circ} \mathrm{C}(\mathrm{cm})\end{array}$ & $\begin{array}{c}\text { Softing } \\
\text { Point }\left({ }^{\circ} \mathrm{C}\right)\end{array}$ \\
\hline MM & 75 & 16 & 56 & 44.7 & 8 & 58.5 & 47.3 & 10 & 57.5 \\
\hline $\mathrm{DH}$ & 68 & 17 & 54 & 39.9 & 7 & 55.5 & 52.2 & 9 & 56.5 \\
\hline IS & 70 & 18 & 56 & 47.4 & 11 & 57.5 & 53.6 & 15 & 57 \\
\hline SBS & 71 & $>150$ & 71 & 55 & 76 & 72.5 & 48.9 & 86 & 71 \\
\hline MM3283 & 38.7 & $>150$ & 71.5 & 35.3 & 36 & 73.5 & 38.5 & 46 & 72.5 \\
\hline MM4283 & 40.2 & $>150$ & 71.5 & 41 & 39 & 74.5 & 35 & 52 & 71.5 \\
\hline DH3283 & 41.1 & $>150$ & 66.5 & 33.6 & 32 & 66.5 & 43 & 51 & 65 \\
\hline DH4283 & 39.7 & $>150$ & 69.5 & 38.3 & 37 & 70.5 & 31.5 & 55 & 70 \\
\hline IS3283 & 42.3 & $>150$ & 70.5 & 47.8 & 40 & 70 & 44.3 & 52 & 71.5 \\
\hline IS4283 & 38.7 & $>150$ & 68.5 & 39.1 & 35 & 67.5 & 35.1 & 49 & 68 \\
\hline
\end{tabular}

In order to study the relationship and influence of thermal oxidative aging and ultraviolet aging on the macroscopic properties of asphalt and its molecular components, two kinds of aging tests are designed. In the thermal oxidative aging test, the rolling thin film oven test method (RTFOT) is used to simulate the aging process of asphalt. The aging time is 5 hours; the test temperature is $163{ }^{\circ} \mathrm{C}$. In the ultraviolet aging test, polymer UV aging box is adopted. The aging time is 5 hours; the UV intensity is $8000 \mu \mathrm{w} / \mathrm{cm}^{2}$ [8-9]. These tests are preformed without heating. There are light heat dissipation effect and the increase of asphalt temperature. In the tests, the surface temperature of asphalt is controlled lower than $100^{\circ} \mathrm{C}$. The data of two kinds of asphalt after aging are shown in Table 2. 


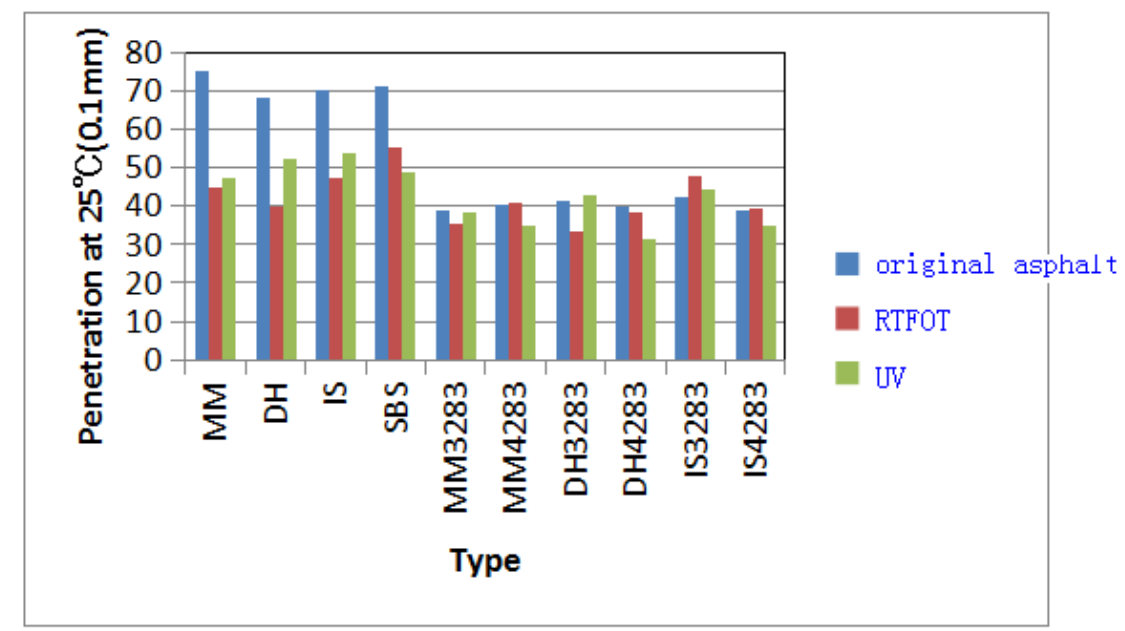

Figure 1. Penetration at $25^{\circ} \mathrm{C}(0.1 \mathrm{~mm})$ of two types of asphalts after aging

The most sensitive part of asphalt after aging is Penetration. From Figure 1 we can see that, after 5 hours RTFOT aging and 5 hours UV aging, the penetration degrees of matrix asphalt decrease obviously. According to the research of Yi-qiu Tan, ultraviolet aging and thermal oxidative aging can reduce the amount of aromatic fragrance (Ar) and increase the number of colloid (R) in asphalt; asphalt become brittle and hard. [10] After two kinds of aging, the needle penetration of SBS modified asphalt also declines. However, the needle penetration of SBS modified asphalt after UV aging is $48.9(0.1 \mathrm{~mm})$, which is smaller than the needle penetration after RTFOT aging $(55(0.1 \mathrm{~mm}))$, indicating that SBS modified asphalt is more sensitive to UV aging. The addition of RPRS can reduce the penetration of asphalts, while the influence of ultraviolet aging on the penetration of the RPRS modified asphalt is relatively small. Analyzing the influences of RPRS3283 and RPRS4283 on the penetration degrees of MM, DH and IS asphalts, it can be found that the penetration of MM3283, DH3283 and IS3283 vary little after RTFOT aging and UV aging; the penetration of MM4283, DH4283 and IS4283 changes relatively greatly after RTFOT aging and UV aging; the penetration of MM4283, DH4283 and IS4283 vary little after RTFOT aging, but show declining trend with different degrees after UV aging.

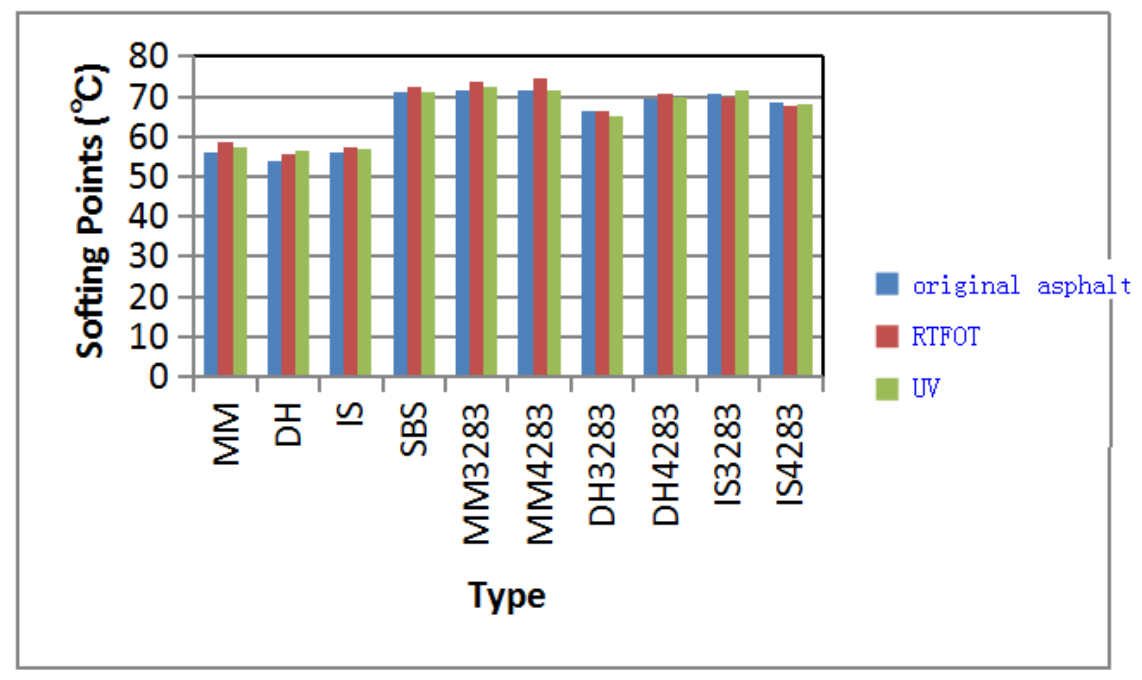

Figure 2. Softing points $\left({ }^{\circ} \mathrm{C}\right)$ of two types of asphalt after aging

There are recycled PE raw materials in RPRS. Heat stabilizers exist in these raw materials when they are produced. But there're less light stabilizers. So RPRS modified asphalt can resist some amount of heating and aging, but it is sensitive to ultraviolet radiation. The difference between RPRS3283 and RPRS4283 lies in the amount of crumb rubber in PR. The proportion of crumb rubber in RPRS4283 is 10\% more than crumb rubber in RPRS3283.

From Figure 2, it can be seen that the Softening Points of various asphalts do not changed greatly 
after RTFOT and UV. The softening point of the matrix asphalt rises slightly. The softening points of SBS modified asphalt and RPRS modified asphalt increase to a certain extent. The RPEW heat stabilizer in RPRS plays a role in resisting thermo-oxidative aging and ultraviolet aging.

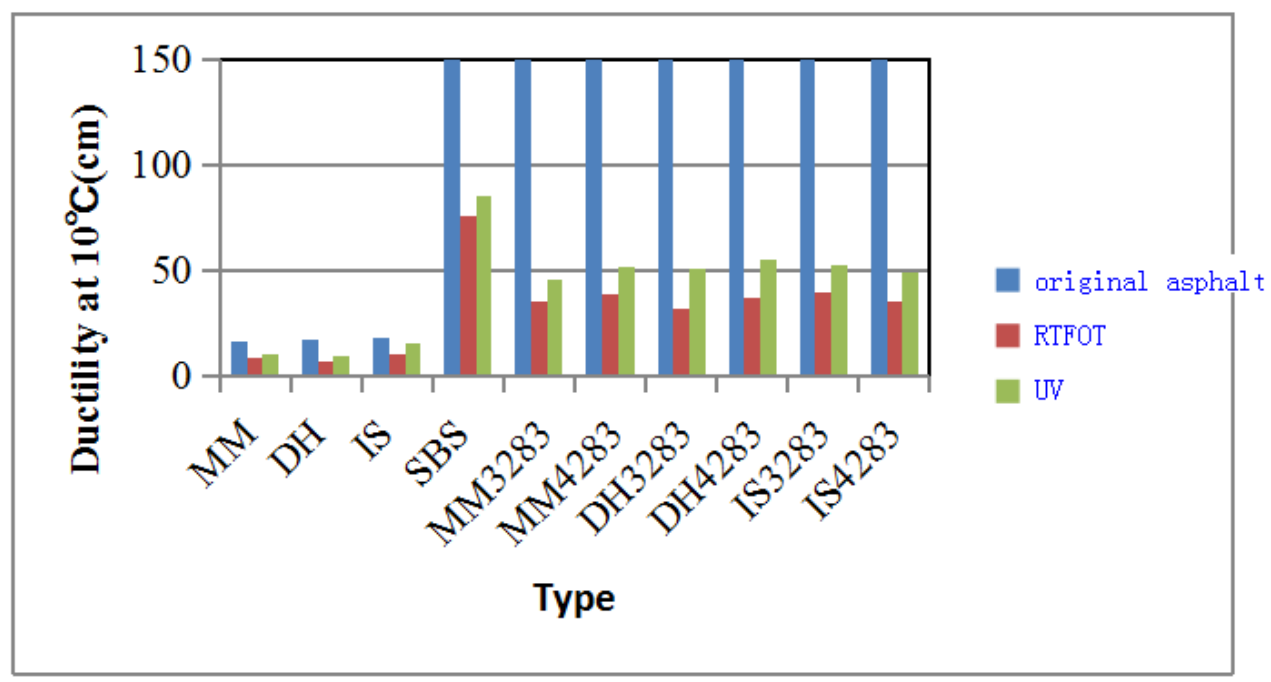

Figure 3. Ductility at $10^{\circ} \mathrm{C}(\mathrm{cm})$ of two types of asphalt after aging

Thermo-oxidative aging and ultraviolet aging have larger effects on the Ductility of asphalts. The aging of road asphalts is the result of reactions between active groups in asphalt and oxygen and ultraviolet in the air. The aging products are mainly carbonyl and sulfoxide functional groups; deep aging may produce carboxyl functional groups. [11-12] After aging, the association and polycondensation of molecules increase the average weight of asphalt molecules. From the analysis of composition and properties it can be found, after aging, the colloid in asphalt decreases; the asphaltene increases; the Softening Point and viscosity increase; the needle Penetration and Ductility decrease.

The Ductility of matrix asphalt decreases obviously at 10 degrees; it decreases more than $50 \%$ after RTFOT aging. After UV aging, it decreases more than 40\%. The Ductility of SBS modified asphalt also decreases obviously at 10 degree. It decreases more than $40 \%$ after RTFOT aging. After UV aging, it decreases more than 30\%. The Ductility of RPRS modified asphalt also decreases obviously at 10 degree. It decreases more than 50\% after RTFOT aging and decreases more than 30\% after UV aging.

\section{Conclusion}

According to the penetration classification system of China, the Penetration of RPRS modified asphalt is lower than that of the matrix asphalt and SBS modified asphalt; its Softening point is higher than that of the matrix asphalt, and varies little from SBS modified asphalt; its Ductility at $10^{\circ} \mathrm{C}$ shows obvious advantages compared with the matrix asphalt, and shows little difference from SBS modified asphalt. The needle penetration index of RPRS modified asphalt is much lower than that of matrix asphalt, indicating that the temperature sensitivity is reduced.

The ultraviolet aging box is used in the aging of matrix asphalt, SBS modified asphalt and RPRS modified asphalt. Then the performances of asphalts after thermo-oxidative aging and ultraviolet aging are analyzed comparatively. Generally speaking, after the thermo-oxidative aging and ultraviolet aging, the Penetration degrees of asphalts reduce; the Softening Points increase; the Ductility degrees decrease. But the ultraviolet aging has less influence than thermo-oxidative aging; thermo-oxidative aging is the main cause of asphalt aging.

\section{References}

[1] A.Q. Shen, J. Fu, M.G. Li, et al., Research on the performance of domestic SBS_PE_SBR 
modified Lanlian asphalt, J. Highways \& Transportation in Inner Mongolia. 3(2000).

[2] Z. Yang, Y. Weng, Y.M. Xu, Study on road performance of polyethylene and its composite modified asphalt, J. Petroleum Asphalt. 4(1998).

[3] W.M. Lv, L.H. Li, Comparison on the performance of several kinds of polymer modified asphalts, J. Petroleum Asphalt. 3 (1998).

[4] K. Li, X.W. Yang, Study on technical problems of polyethylene modified asphalt, J. China Elastomerics. 4 (2008).

[5] A.Q. Shen, J. Fu, S.J. Wang, et al., Research on road performance of domestic modified asphalt of UINTAHITE, PE and SBR composite and its SMA mixture, J. Petroleum Asphalt. 3 (1998).

[6] T. Mei, Y.L. Chi, Y.G. Yi, et al., Study on properties of high density polyethylene pyrolysis of polyethylene wax, J. China Petroleum Processing Petrochemical Technology. 11 (2011).

[7] J.Z. Huang, Research progress on waste polyethylene pyrolysis to polyethylene wax, J. Journal of Guangdong University of petrochemical technology. 6 (2014).

[8] J.N. Wang, Z.J. Xue, Y.Q. Tan, Effect of ultraviolet aging on the mechanical behavior and aggregation of asphalt, J. China Journal of Highway and Transport. 6 (2011).

[9] J.N. Wang, Study on aging mechanism and rheologic behavior of asphalt under simulate ultraviolet environment, Harbin Institute of Technology, Harbin, 2008.

[10] Y.Q. Tan, J.N. Wang, Z.L. Feng, et al., The mechanism of UV aging of asphalt binder, J. China Journal of Highway and Transport. 7 (2008).

[11] F. Ye, D.Q. Sun, P. Huang, et al., Analysis of strong ultraviolet light aging properties of asphalt, J. China Journal of Highway and Transport. 6 (2006).

[12] R.M. Wei, Research on the aging and regeneration of bitumen, Wuhan University of Technology, Wuhan, 2006. 